\title{
Incorporation of High-Altitude Balloon Experiment in High School Science Classrooms
}

\author{
Stephen Cheng1, David Gerhard², Fidji Gendron³, Vincent Ziffle ${ }^{3}$ \\ ${ }^{1}$ Department of Chemistry and Biochemistry, University of Regina, Regina, Canada \\ ${ }^{2}$ Department of Computer Science, University of Regina, Regina, Canada \\ ${ }^{3}$ Department of Indigenous Science, The Environment and Economic Development, First Nations University of Canada, \\ Regina, Canada \\ Email: Stephen.Cheng@uregina.ca
}

How to cite this paper: Cheng, S., Gerhard, D., Gendron, F., \& Ziffle, V. (2019). Incorporation of High-Altitude Balloon Experiment in High School Science Classrooms. Creative Education, 10, 262-272. https://doi.org/10.4236/ce.2019.102021

Received: December 20, 2018

Accepted: February 11, 2019

Published: February 14, 2019

Copyright (C) 2019 by author(s) and Scientific Research Publishing Inc. This work is licensed under the Creative Commons Attribution International License (CC BY 4.0).

http://creativecommons.org/licenses/by/4.0/

\begin{abstract}
We have been launching high-altitude balloons to engage students in science since 2013. Our custom balloon kit allows high school teachers and students to collect environmental data and capture videos. Through our experience interacting with high school students, we have found that the high-altitude balloon experiment is an effective tool for inquiry-based learning to introduce chemistry topics including gas properties, elements and molecules, heat capacity, thermochemistry, electromagnetic radiation, bond breaking and formation, and atmospheric chemical reactions. Examples are given to demonstrate how to incorporate the experiment in high school science classrooms.
\end{abstract}

\section{Keywords}

High-Altitude Balloon Experiment, Inquiry Based Learning, Science Activity, Chemistry Topics, STEM

\section{Introduction}

Educators from many post-secondary institutions have been launching high-altitude balloons to engage university students in science and engineering for more than ten years. Larson, Armstrong, and Hiscock (2009) first described how they used high-altitude ballooning to provide a hands-on experience to engage university students in physics, atmospheric science, engineering, and other aerospace disciplines. Voss, Dailey, and Snyder (2011) launched hSigh-altitude balloons with their introductory astronomy students and they found that the experiment improves the learning outcome of their students. Coleman and Mitchell (2014) discussed the incorporation of a high-altitude balloon experiment in atmospher- 
ic science courses and how the experiment successfully engages students, improving student success.

More recently, several university educators reported that they have been adapting high-altitude balloon experiments for middle school and high school students. Tillman, Roberts, and Fuller (2008) first described their work to use high-altitude balloon studying near space to engage high school students. Straub, Ingwalson, and Fevig (2013) proposed a design of a high-altitude balloon experiment for middle school curriculum to engage Grades 6 - 8 students. Beck-Winchatz and Bramble (2014) discussed how high-altitude ballooning has been used to carry out life science research with middle school and high school students. Their research studied the effects of solar cosmic rays and ultraviolet radiation on yeast and plant seeds. Saad (2014) reported how near-space ballooning was successfully used to engage Grade 8 Earth Science students in science, technology, engineering, and mathematics (STEM) education in North Dakota. Hike and Beck-Winchatz (2015) described the use of high-altitude balloons project for their International Baccalaureate Middle Years Programme chemistry course. Fong, Kennon, and Roberts (2016) described how they incorporated the high-altitude balloon in high school physical science classrooms. Finally, Taylor and Nero (2017) described the development of Project HALON to engage secondary students in Nebraska.

Launching a high-altitude balloon is fun and exciting. We and our partners have launched more than 35 helium balloons with middle school, high school, and post-secondary students since 2013. All participants have appreciated the experience and most of them have expressed interest to do a second launch from the results of our preliminary research. Through our interactions with high school teachers, we have learned that we can bring the high-altitude balloon experiment to its full potential by incorporating the project into the classrooms. Thus, we hypothesize that integrating the high-altitude balloon experiment with chemistry topics into high school science classrooms can make the project more effective. In this paper, we will provide a brief discussion of our high-altitude balloon kit, the typical data collected by our system, and discuss how the high-altitude balloon experiment has been used to engage students in specific chemistry topics using inquiry-based learning, as well as constructing knowledge using the collected data from the balloon launch.

\section{Development of High-Altitude Balloon Kit}

Our standard balloon kit comes with an onboard Arduino-based computer containing sensors measuring temperature, atmospheric pressure, humidity, global positioning system (GPS) position, and inertia measurement unit (IMU) motion. The kit also has an option to include environmental gas sensors to measure hydrocarbons, ozone, carbon monoxide, nitrogen dioxide, and/or ammonia. We must point out here that the solid-state metal oxide semiconductor gas sensors have limited detecting range and may provide inconsistent data at high altitude; 
the limitations and specifications of the sensors are provided in Supplementary Materials (Fine, Cavanagh, Afonja, \& Binions, 2010; Korotcenkov \& Cho, 2012; Wang, Yin, Zhang, Xiang, \& Gao, 2010). Metal oxide semiconductor gas sensors were chosen because the data from the environmental sensors can provide some general idea of the environment while keeping the cost of the complete balloon kit to CAD $\$ 1,000$. There is also a video camera on the payload providing imagery and videos of near space, and allowing students and teachers to carry out interesting experiments. The onboard system can also be easily expanded to include additional detectors and sensors, with open source software and simple hardware specifications to make it easy for teams to add their own experiments. Depending on the experience of the launch team, it takes half an hour to an hour to perform the launch itself. Once the balloon is filled with helium and released with the attached payload, it will ascend to an altitude of $25-28 \mathrm{~km}$. Then, the balloon will burst and the payload will return to the ground using a parachute to control the rate of descent.

Since the onboard computer of the balloon kit contains several sensors that can easily be upgraded to include additional environmental sensors and/or other detectors, a lot of environmental data are collected from each balloon launch. High school teachers can use this collected data in the classroom, providing students with an opportunity to analyze real life scientific data, as well as dealing with real-world challenges of data collection such as sensor calibration, differing collection protocols, and occasional missing data. Further, we have found that the videos captured by the onboard cameras are a very effective tool to engage and motivate students. The video camera can also be used to support some of the experimental data and potentially be used to perform interesting high-altitude balloon experiments.

\section{Data Analysis from Our Balloon Kit}

Larson et al. (2009) has demonstrated how the high-altitude balloon experiment could be used in astronomy and physics education. Following their work, we are able to reproduce the analysis using the data collected by our customized onboard computer and sensors. As shown in Figure 1, the altitude of the payload is plotted against time (UTC $=$ universal coordinated time).

The temperature is plotted against altitude for the ascent of the balloon and the descent of the payload as shown in Figure 2. During the ascent, the temperature first decreases as the altitude increases. After passing around $11 \mathrm{~km}$, the temperature increases as the altitude increases. During the descent, the temperature initially decreases as the altitude decreases above $11 \mathrm{~km}$. Then, the temperature increases as the altitude decreases below $11 \mathrm{~km}$. The temperature change at different altitudes can be used to distinguish the troposphere from the stratosphere. In the troposphere, the temperature decreases at higher altitude. However, in the stratosphere, the temperature increases at higher altitude. Thus, the thickness of the troposphere can be determined by the temperature change at 


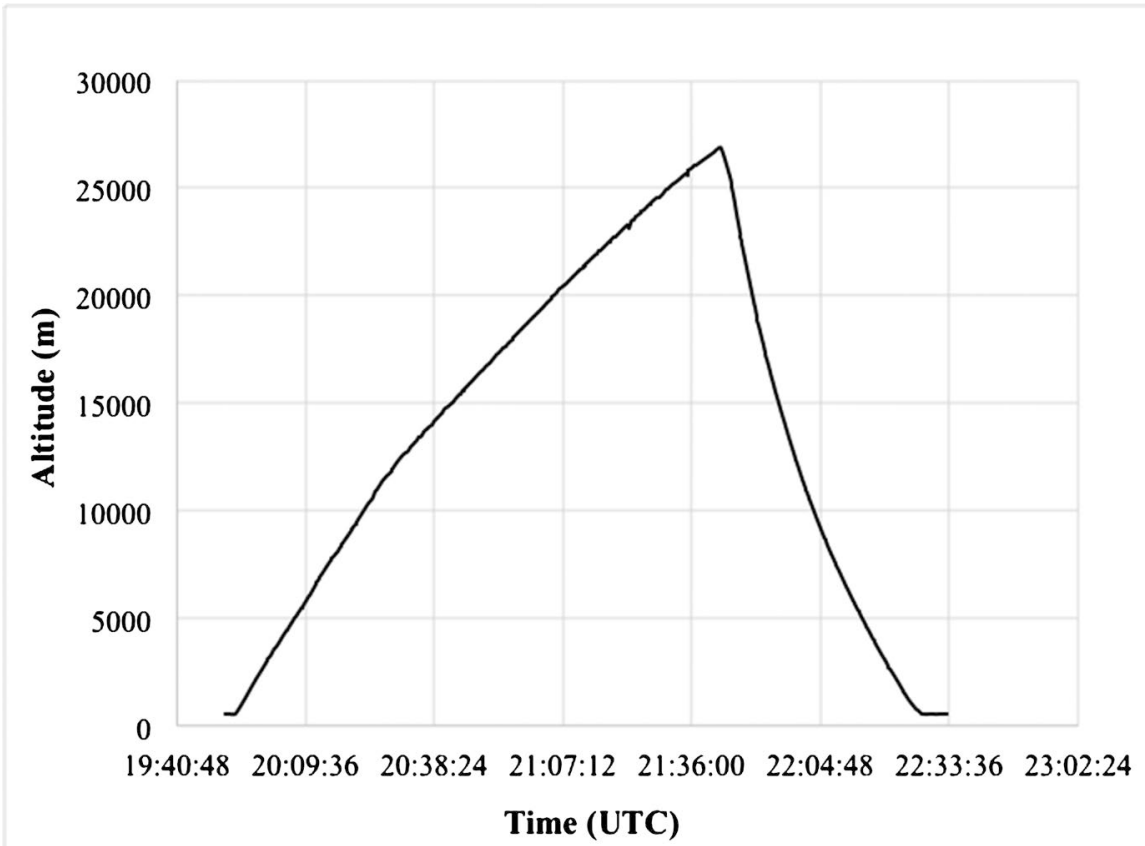

Figure 1. Typical plot of altitude of payload at real time. The ascent rate is higher at the lower altitude than the higher altitude. The descent rate is very fast immediately after the balloon burst but it decreases as the payload falls to lower altitude.

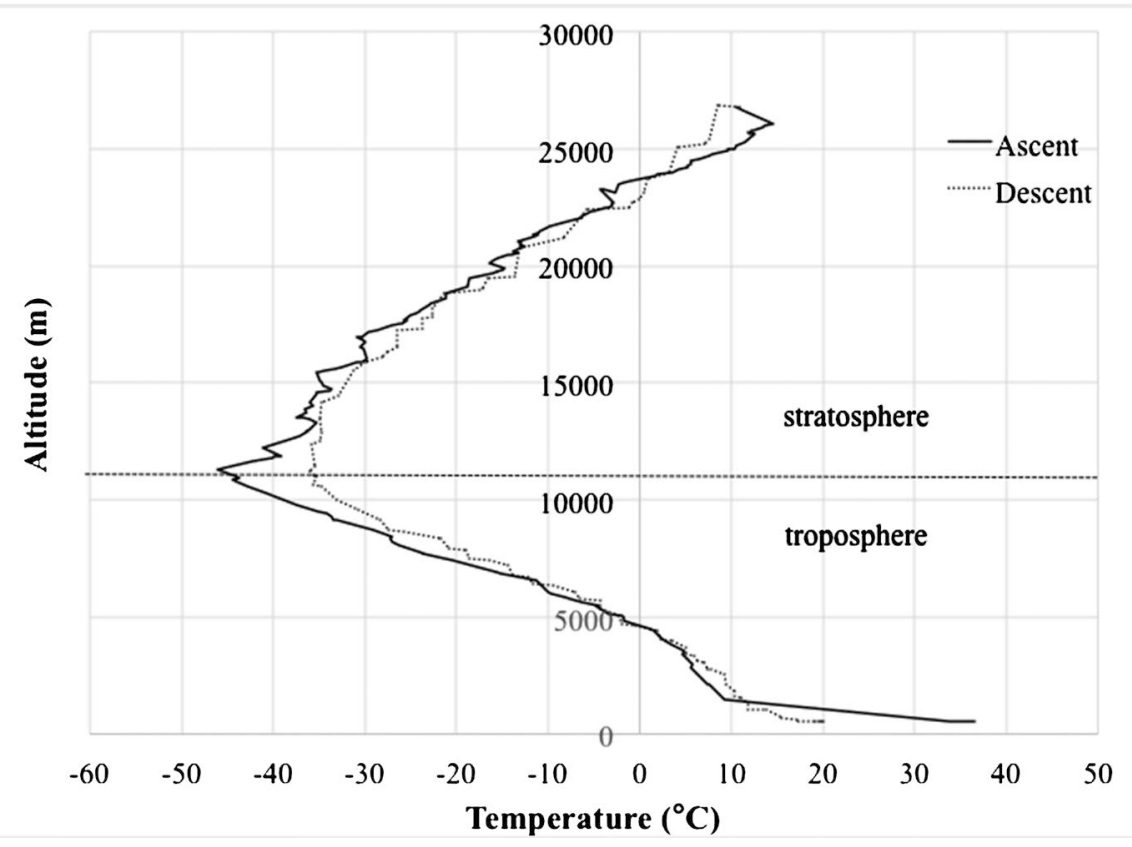

Figure 2. Temperature versus altitude for a typical balloon flight. In the troposphere, the temperature decreases as the altitude increases. In the stratosphere, the temperature increases as the altitude increases. The thickness of the troposphere can be determined from the temperature change at different altitudes. The temperature during ascent of the balloon is shown in blue and the temperature during decent is shown in red.

different altitudes. Generally speaking, the thickness of the troposphere varies at the different latitudes and seasons. The troposphere is thicker along than Equa- 
tor than the North Pole and the South Pole. The troposphere is also thicker in the summer than in the winter.

We have found that although this change in temperature matches with predictive models and experimental results from other researchers, it is still surprising to most students. When asked to predict what will happen to the temperature as the balloon rises, most students predicted that the temperature would decrease with higher altitude. When showing the actual data, and asked to interpret the results, students were often confused and were then encouraged to perform further investigations to discover the cause of the temperature reversal at around $10 \mathrm{~km}$. In this way, we find an opportunity to reinforce the scientific process of forming hypotheses to explain evidence, rather than collecting evidence to support hypothesis. Further, the experiment presented herein shows how a student may be surprised by results from the real world, seek an explanation, and use that explanation to make predictions. If students are interested in launching more balloons, an opportunity would be available to confirm the results by measuring temperature versus altitude; to make predictions about the temperature inflection point and its dependence on weather, seasons, and time of day; and to infer characteristics of the troposphere from this measurement data.

\section{Incorporate Experiment Using Chemistry Topics through Inquiry-Based Learning in Science Classrooms}

In traditional high school science classrooms, students learn the fundamentals mostly from textbooks with some demonstrations and laboratory experience. While teachers often use real life examples to illustrate new concepts to students, many students find the materials dry and sometimes difficult to understand because these novel concepts are often presented as facts rather than discoveries, and there is a deficiency of hands-on experience to connect real life examples to the scientific concepts. With this experiment, we demonstrate how the data collected from the high-altitude balloon experiment have been incorporated in high school science classrooms using chemistry topics through inquiry-based learning. When we are doing balloon launches with middle and high schools, we often give a pre-launch and/or post-launch discussion with the students and teachers so that they can continue the conversation of the project in their classrooms.

\subsection{The Perfect Gas Law and the Balloon Size}

We use $600 \mathrm{~g}$ balloons in our launches. Once the balloon is filled with helium and released, it will rise to an altitude of approximately $25-28 \mathrm{~km}$ and then fall back. Thus, what is happening at this altitude when the balloon stops going up? With the onboard video camera facing upward from the payload, we showed students that the size of balloon increases as it ascends to higher altitude. Then, the balloon bursts once it expands beyond the volume at which the structural 
integrity of the balloon can no longer withhold the pressure of the gas. Students were amazed when they saw the photos of the balloon at the time of launch and right before its burst as shown in Figure 3. Since the temperature, the atmospheric pressure, and the amount of helium in the balloon are known on the ground and at the time the balloon bursts, students can calculate the volume of the balloon at different altitudes using the perfect gas law as described by Fong, Kennon, and Roberts (2015).

Going forward, after students calculate the volume of the balloon on the ground and right before burst, they can compare the volume change with the experimental results from the photos taken. Teachers may use the exercise to discuss the validity of the perfect gas law by comparing the theoretical and experimental results.

\subsection{Density of Air and the Atmospheric Pressure}

The ascent of the balloon is slower than the descent of the payload as shown in Figure 1. Further, the balloon ascends at higher rate at lower altitude than at higher altitude, while the payload descends at a higher rate at higher altitude than at lower altitude. The results can also be visualized from the video footage that the fall of the payload is very fast immediately after the balloon bursts. After showing the physical data and video footage, we asked students how they would correlate the observations to atmospheric pressure and air density. The atmospheric pressure is higher at the lower altitude and lower at higher altitude; thus, the density of air is higher at lower altitude than at higher altitude. However, it
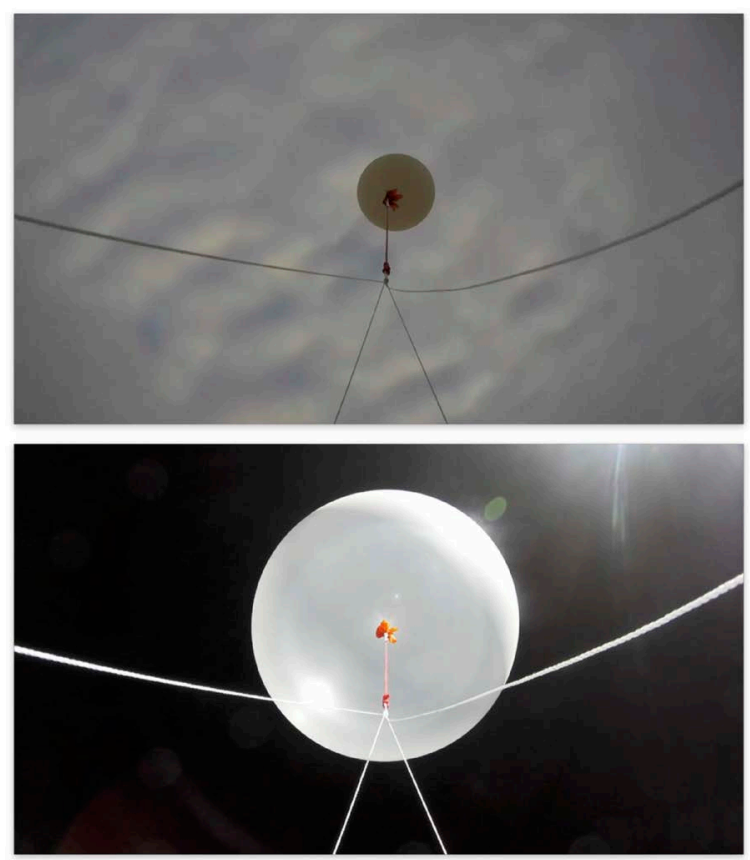

Figure 3. Pictures captured by the onboard video camera facing upward from the payload at launch (left photo) and just before burst (right photo). The two photos are on the same scale and the distance between the camera and the bottom of the balloon is constant. 
may be difficult for some students to see the connection between atmospheric pressure and density of air because students cannot visualize that the atmospheric pressure originates from the masses of the elements and molecules in the air.

The data and the video footage have demonstrated that the ascent of the balloon at lower altitude is faster than at higher altitude, because there is a higher density of air at lower altitude than at higher altitude increasing the buoyancy of the balloon at the lower altitude. Immediately after the burst of the balloon, even with the deployment of the parachute, there is very low density of air to slow the fall of the payload, resulting in the quick fall. Once the payload falls to the lower altitude in the troposphere with higher density of air, the parachute would engage and begin to slow the fall of the balloon. Since the atmospheric pressure is measured at different altitudes, we concluded that the atmospheric pressure is found to be higher at lower altitude and it must be related to the higher density of air.

Going forward, students can calculate the air density from the atmospheric pressure and the composition of air. The activity can help students understand the theoretical basis of the correlation of the atmospheric pressure and air density. Further, teachers can use the exercise to elaborate the elements and molecules found in the atmosphere.

\subsection{Heat Capacity and the Temperature Change in the Troposphere}

As shown in Figure 2, the temperature decreases as the balloon ascends to higher altitude of approximately $10-12 \mathrm{~km}$ in the troposphere. After showing the graph of temperature change vs. altitude, we asked students to come up with an explanation of the observation. Since they may not have the prior knowledge to interpret the data, we would tell them that the troposphere is warmed by the energy from the Sun; thus, one would expect that the temperature should be higher at higher altitude but that is not what is observed. From earlier discussions, the atmospheric pressure is lower and thus the density of air decreases as the altitude increases. With lower atmospheric pressure, there are far fewer gas molecules at higher altitude. Since temperature is related to the amount of heat that is held by a substance, fewer gas molecules translate to less heat held by these molecules and lower temperature. Thus, we illustrated the concept of heat capacity and how it contributes to the higher temperature at lower altitude.

Going forward, students can determine the amount of heat that can be held at different altitudes using air density, composition of air, and heat capacity of each component of air. The exercise will help students better understand the concept of heat capacity and heat transfer.

\subsection{Enthalpy Change of the Formation and Dissociation of Ozone}

The temperature decreases at higher altitude in the troposphere and we said in the previous paragraph that it is related to the lower heat content at higher alti- 
tude. Thus, one would expect that the temperature would keep getting lower as the altitude increases. Two other reasons students often predict that the temperature decreases as altitude increases: they have experienced that as you climb a mountain, the temperature decreases; and they know that it is very cold in space. These two observations may lead students to believe that temperature would decrease monotonically as altitude increases. However, once the altitude passes approximately $11 \mathrm{~km}$, the temperature starts to increase at higher altitude. Thus, we cannot use heat capacity to explain the phenomenon since the air should get even thinner as the altitude increases in the stratosphere.

When we had an ozone sensor onboard the payload, we found that there is an increasing concentration of ozone once the balloon reaches $11 \mathrm{~km}$. Thus, we asked students to propose how the presence of ozone may cause the temperature to increase at higher altitude in the stratosphere. Students may not know anything about ozone and how it is formed in the atmosphere. To encourage them to inquire ozone, we asked them to consider why ozone is found in the stratosphere above $11 \mathrm{~km}$ rather than the troposphere and provide them the following background information.

In the stratosphere, there is a large amount of high energy electromagnetic radiation. The electromagnetic radiation has enough energy to break the oxygen-oxygen double bond of molecular oxygen forming monatomic oxygen. Monatomic oxygen is very reactive and it will react with molecular oxygen to form ozone. The chemical process is exothermic, meaning that heat is released. Thus, the fact that the temperature increases at higher altitude in the stratosphere is resulted from the formation of ozone. As it turns out, the generation of ozone is not sufficient to explain the increased temperature in the stratosphere. This increasing temperature at higher altitude is also related to the decomposition of ozone. Ozone will decompose to form molecular oxygen in the presence of electromagnetic radiation. In the presence of electromagnetic radiation with sufficient energy, ozone will decompose to molecular oxygen and the process is also exothermic that releases heat. As a result, the two processes contribute to the temperature increase in the stratosphere as the altitude increases.

Going forward, students can verify what we told them by calculating the enthalpy change of reaction using average bond enthalpies and/or the standard enthalpies of formation of the reactants and products. Further, teachers may use the exercise to ignite students' interest in bond breaking, bond formation, and chemical reaction.

\section{Research on the Effectiveness of Our Approach}

We recently worked with two teachers to incorporate the high-altitude balloon experiment in their science classrooms. We also did a preliminary survey with the two teachers and their students. For the teachers, we asked them whether their students learned more during the data analysis once the payload was retrieved. For the students, we asked them about an example of science that they 
Table 1. Written comments provided by students who participated in the high-altitude balloon experiment.

An Example of Science Learned during the Project:

"The temperature that changes high in the sky".

"I have learned that the air is thinner in the ozone layer".

"Time, temperature, $\mathrm{km}$ of the balloon".

Part of the Project That They Liked the Most:

"I liked the data".

"Watch the video cause we got to see how everything looked".

"Launch the balloon because it was pretty. Cool seeing how big it got".

"The excitement, all the students and teachers were excited to see the science happening at the site; everyone cheering at the time of launch".

learned and the part of the project they liked most.

\section{Preliminary Results from Students and Teachers}

The two teachers both strongly agreed that their students learned more during the data analysis once the payload was retrieved. When we asked the teachers how they incorporated the balloon experiment in their classroom, one teacher commented that "we have used the balloon launch to understand concepts and teachings and with our land-based teaching". Another teacher wrote that "we are studying elements and compounds in Science 10".

We have also received the following written comments from students who participated in the survey (Table 1). The responses from the students suggest that the high-altitude balloon experiment is engaging and our approach to use inquiry-based learning and chemistry topics is effective in high school science classrooms.

\section{Conclusion}

We have successfully developed a high-altitude balloon kit and a complete set of instructions that allowed educators to engage their students in science and engineering. Further, through our interactions with high school teachers and students, we have found that we can enhance the impact of the high-altitude balloon experiment by incorporating the project into science classrooms. With the inquiry-based learning approach using experimental data collected during the balloon experiment, chemistry topics, including gas law, gas properties, elements and molecules, heat capacity, endothermic and exothermic processes, electromagnetic radiation, bond formation, and atmospheric chemical reactions can be effectively introduced in high school science classrooms.

\section{Acknowledgements}

We would like to thank our students at the University of Regina who participated 
in the High-Altitude Balloon Experiment Program. We would also like to thank our partners including middle schools and high schools in Saskatchewan, post-secondary institutions across Canada, and Science Rendezvous that participated in balloon launches. The program was made possible by the financial support of the following organizations and grants: NSERC PromoScience grant, TD Friends of the Environmental Foundation grant, the University of Regina Indigenous fund, and the Faculty of Science at the University of Regina. Finally, publication support was provided by the University of Regina President's Publication Fund.

\section{Conflicts of Interest}

The authors declare no conflicts of interest regarding the publication of this paper.

\section{References}

Beck-Winchatz, B., \& Bramble, J. (2014). High-Altitude Ballooning Student Research with Yeast and Plant Seeds. Gravitational \& Space Biology, 25, 117-127.

Coleman, J. M., \& Mitchell, M. (2014). Active Learning in the Atmospheric Science Classroom and beyond through High-Altitude Ballooning. Journal of College Science Teaching, 44, 26-30. https://doi.org/10.2505/4/jcst14_044_02_26

Fine, G. F., Cavanagh, L. M., Afonja, A., \& Binions, R. (2010). Metal Oxide Semi-Conductor Gas Sensors in Environmental Monitoring. Sensors, 10, 5469-5502. https://doi.org/10.3390/s100605469

Fong, B. N., Kennon, J. T., \& Roberts, E. (2015). Weather Balloon Activity Helps Students Understand Ideal Gas Laws. Tech Directions, 75, 32-36.

Fong, B. N., Kennon, J. T., \& Roberts, E. (2016). Integrating BalloonSAT and Atmospheric Dynamic Concepts into the Secondary Classroom. The Physics Teacher, 54, 264-267. https://doi.org/10.1119/1.4947150

Hike, N., \& Beck-Winchatz, B. (2015). Near Space Science: A Ballooning Project to Engage Students with Space beyond the Big Screen. The Science Teacher, 82, 29-36.

Korotcenkov, G., \& Cho, B. K. (2012). Ozone Measuring: What Can Limit Application of $\mathrm{SnO}_{2}$-Based Conductometric Gas Sensors. Sensors and Actuators B: Chemical, 161, 28-44. https://doi.org/10.1016/j.snb.2011.12.003

Larson, S. L., Armstrong, J. C., \& Hiscock, W. A. (2009). The First Frontier: High-Altitude Ballooning as a Platform for Student Research Experiences in Science and Engineering. American Journal of Physics, 77, 489-497. https://doi.org/10.1119/1.3097775

Saad, M. E. (2014). Progressing Science, Technology, Engineering, and Math (STEM) Education in North Dakota with Near-Space Ballooning. Master's Thesis, Grand Forks, SD: University of North Dakota.

Straub, J., Ingwalson, G., \& Fevig, R. (2013). A Design for Inspiring Students with Near-Space Exploration. Journal of Aviation/Aerospace Education \& Research, 23, 35-48. https://doi.org/10.15394/jaaer.2013.1597

Taylor Jr., J. M., \& Nero, D. A. (2017). Project HALON: Engaging Secondary Students in High-Altitude Ballooning Experiments. In 2017 IEEE International Conference on Electro Information Technology (pp. 587-592). Lincoln, NE: IEEE. 
https://doi.org/10.1109/EIT.2017.8053432

Tillman, K., Roberts, E., \& Fuller, T. (2008). Students at the Edge of Space: A Collaborative Program Using BallonSats Allows Students to Investigate Space. The Science Teacher, 75, 37-43.

Voss, H. D., Dailey, J., \& Snyder, S. J. (2011). High-Altitude Balloon Curriculum and Hands-on Sensors for Effective Student Learning in Astronomy and STEM. In J. B. Jensen, J. G. Manning, \& M. G. Gibbs (Eds.), Earth and Space Science: Making Connections in Education and Public Outreach (pp. 340-344). San Francisco: Astronomical Society of the Pacific.

Wang, C. X., Yin, L. W., Zhang, L. Y., Xiang, D., \& Gao, R. (2010). Metal Oxide Gas Sensors: Sensitivity and Influencing Factors. Sensors, 10, 2088-2106.

https://doi.org/10.3390/s100302088

\section{Supplementary Materials: Limitations and Specifications of Metal Oxide Semiconductor Gas Sensors}

Metal oxide semiconductor gas sensors are used to measure the concentration of ammonia, carbon monoxide, nitrogen dioxide, ozone, and VOC. These sensors determine the concentration of the gases by measuring the change in the resistance of the metal oxide film in the presence and the absence of the detectable gases. Since the sensors depend on the surface chemistry of oxygen adsorbed on the metal oxide film, the atmospheric pressure, humidity, and the operating temperature will affect the resistance of the film. Thus, at high altitude with reduced atmospheric pressure and extremely low temperature, the resistance of the metal oxide film will become inconsistent.

The models and specifications of the sensors used in the program are shown below:

\begin{tabular}{cccc}
\hline Model & Detectable Gas & Detecting Range & $\begin{array}{c}\text { Operating } \\
\text { Temperature }\end{array}$ \\
\hline MiCS-2614 & Ozone & $10-1000 \mathrm{ppb}$ & $-40^{\circ} \mathrm{C}-70^{\circ} \mathrm{C}$ \\
MiCS-6814 & Ammonia & $1-300 \mathrm{ppm}$ & $-30^{\circ} \mathrm{C}-85^{\circ} \mathrm{C}$ \\
& Carbon monoxide & $1-1000 \mathrm{ppm}$ & \\
& Nitrogen dioxide & $0.05-10 \mathrm{ppm}$ & $0-50^{\circ} \mathrm{C}$ \\
\hline
\end{tabular}

